\title{
A inserção da música na escola: processos e resultados de uma pesquisa
}

\author{
CARLA EUGENIA LOPARDO
}

Doutora em Música, com ênfase em Educação Musical, pela Universidade Federal de Rio Grande do Sul (Porto Alegre, Brasil), mestre em Didática da Música, pela Universidad Caece (Buenos Aires, Argentina) e professora de Educação Musical pelo Conservatório Superior de Música Manuel de Falla (Buenos Aires, Argentina). Tem experiência na área de Artes: Música, em todos os níveis de ensino, no âmbito público e privado, atuando principalmente na formação de professores; musicalização para crianças, jovens e adultos; produção de materiais didáticos; multiculturalismo musical; avaliação e pesquisa em educação musical. É professora adjunta da Universidade Federal do Pampa (UNIPAMPA), a cargo dos componentes pedagógico-musicais no Curso de Música/Licenciatura, coordena projetos de extensão que oferecem para a comunidade cursos de musicalização para bebês e crianças, espaços de criação musical coletiva com o projeto "Confraria de la Yerba" e práticas vocais coletivas com o grupo infanto-juvenil "Baque do Pampa". Além disso, orienta projetos de iniciação à pesquisa e atua como orientadora no contexto dos estágios supervisionados em música. Autora do livro "A música na escola: tempos, espaços e dimensões" (Editora Appris, 2018). Membro do conselho editorial do Boletín de Investigación Educativo-Musical (BIEM) da Asociación de Docentes de Música (ADOMU), representante da International Society for Music Education (ISME) na República Argentina. Participa do Grupo de Pesquisa Educação Musical e Cotidiano (EMCO) da UFRGS realizando projetos interdisciplinares, ministrando cursos e palestras, com publicação de artigos em revistas nacionais e internacionais (<http://lattes.cnpq.br/3922573309511736>).

AFILIAÇÃO: Universidade Federal do Pampa (Unipampa), Bagé, Rio Grande do Sul. 


\section{- RESUMO}

Neste artigo apresento minha tese de doutorado a qual teve como propósito observar, analisar e discutir os caminhos que uma escola particular na região sul do Brasil percorre ao implementar a Lei 11.769/08, a qual tornava obrigatório o ensino da música nas escolas, em todos os seus níveis de ensino. O método escolhido, desde uma abordagem qualitativa, foi o estudo de caso e as técnicas de produção de dados foram a entrevista semiestruturada, a observação participante, os diários de campo e as discussões com grupos focais. Na realização desta pesquisa procurei compreender os processos e as linhas de ação colocadas em prática desde os primeiros passos da inserção da música na escola e, posteriormente, analisar os impactos dessa inserção no contexto escolar. A partir dos achados desta investigação observei determinados elementos vinculados à inovação escolar: a disposição para a mudança, o envolvimento de/com cada uma das dimensões da escola e a presença de uma gestão democrática participativa, atravessando por situações de adaptação, ajuste, reflexão e avaliação sobre os reflexos da presença da música no dia a dia dessa escola.

- PALAVRAS-CHAVE

Educação musical, inovação, cotidiano escolar, estudo de caso.

\section{ABSTRACT}

In this article I present my doctoral thesis whose purpose was to observe, analyze and discuss the ways that a private school in the southern region of Brazil goes through the implementation of Law 11.769 / 08, which made compulsory the teaching of music in schools, in all levels of education. The method chosen from a qualitative approach was the case study and the techniques of data production were semistructured interview, participant observation, field diaries and discussions with focus groups. In this research I tried to understand the processes and the lines of action put into practice from the first steps of the insertion of the music in the school and, later, to analyze the impacts of this insertion in the school context. Based on the findings of this research, I have observed certain elements related to school innovation: the willingness to change, the involvement of / with each of the dimensions of the school and the presence of participatory democratic management, going through situations of adaptation, adjustment, reflection and evaluation of the reflexes of the presence of the music in the day to day of this school.

\section{KEYWORDS}

Music education, innovation, school routine, case study. 


\section{Introdução}

A pesquisa aqui apresentada abriu a discussão sobre as múltiplas possibilidades da inserção da música no ambiente escolar, observando e analisando os diferentes caminhos que uma escola percorre ao introduzir o ensino de música em todos os seus níveis de ensino. A experiência da escola apresentada nesta investigação de doutorado permitiu compreender o(s) impacto(s) dessa inserção a partir do olhar de cada uma das partes de sua comunidade numa realidade social, política e econômica em constante mudança e transformação. Contudo espera-se que a leitura deste artigo possa aproximar ao professor de música, ao licenciando ou ao diretor de escola, dos procedimentos e reflexos produzidos nesta comunidade escolar podendo transferir a outras realidades a experiência aqui relatada, incentivando a reflexão sobre diferentes modalidades e visões de construção do espaço da música no ambiente escolar.

Os conceitos sobre inovação e cotidiano escolar permeiam as discussões sobre os modos de conhecer e fazer música, assim como os espaços e as dimensões que a música assume no ambiente escolar. Foram pesquisados os processos de análise, avaliação, adaptação, perdas e ganhos que a presença da música provoca não somente na matriz curricular de uma instituição, mas também nas pessoas, nas concepções sobre o que representa e como a música está presente no ambiente escolar, que papel e funções ela desenvolve, em quais espaços da vida escolar ela se insere, constrói-se, desenvolve-se e transcende. Nessa direção, tento dialogar com os diferentes significados e concepções sobre educação musical que são construídos com a vivência da música nos múltiplos espaços-tempos escolares, colocando em discussão conceitos como gestão democrática participativa, currículo musical heterogêneo, identidade escolar e construção do conceito de educação musical no ambiente escolar.

A minha busca esteve centrada em mostrar essas encruzilhadas como respostas aos diversos momentos do processo de inserção da música, tendo como desafio o fato de revelar a vida cotidiana da comunidade estudada na "textura da aparente rotina de todos os dias" na perspectiva de José Machado Pais e Nilda Alves, sem prestar demasiada atenção nos fatos por si só, mas principalmente no modo como me aproximava deles, o modo como os interrogava e revelava. Seguindo essa forma de enxergar a realidade, mergulhando nas situações cotidianas com as quais me deparava, fui tecendo as redes que davam sentido às diferentes versões sobre a presença da música na escola.

As vozes de cada uma das partes envolvidas nesse processo foram ouvidas, percebidas e contextualizadas por meio da realização de um conjunto de entrevistas, de discussões com grupos focais, a escrita dos diários de campo, as conversas "de corredor", os registros de experiências musicais dentro e fora da sala de aula, em tempos e espaços diversificados, que permitiram criar uma base de dados significativos, observando as interseções e os cruzamentos entre as diferentes vozes dessa realidade.

A pesquisa desenvolveu-se entre os anos 2010 e 2014, numa escola particular na Zona Norte de Porto Alegre/RS, na qual desenvolvi minhas atividades como professora de música ao mesmo tempo em que olhava para essa realidade como 
campo de estudo e pesquisa. Neste artigo serão abordados, de forma sucinta, os processos de construção da pesquisa, revisitando os autores que fundamentaram minhas escolhas conceituais e metodológicas.

\section{Fundamentação Teórica}

Diante da implementação da já revogada Lei $11.769 / 08^{1}$, a música no currículo da instituição estudada se estabeleceu como uma situação a ser resolvida seguindo determinadas linhas de ação na intenção de reconhecer um espaço para a educação musical. Junto a isso, apareceram questões relacionadas às múltiplas funções da música na escola e essas questões dizem respeito à finalidade da educação musical como disciplina obrigatória ou como conteúdo curricular; às competências que os alunos deveriam desenvolver dentro desta área; ao perfil do professor de música e, finalmente, ao significado da música em relação à construção do conceito de educação musical escolar.

Para dar resposta a estas questões, foi necessário estabelecer um modo de perceber e olhar para aquela situação. Os dois aspectos que se constituíram como guias no processo de observação e análise da inserção da música na escola se apoiam nas concepções sobre inovação e cotidiano escolar de pensadores como Aguerrondo (2002), Carbonell (1998; 2002), Nóvoa (2009), Tedesco (2001), Alves (2001e 2004), Certeau (1994), Heller (2000), Pais (1993) e Souza (2000; 2008). Segundo Aguerrondo (2002), todo processo de inovação surge como resposta diante de uma necessidade e essa resposta apresentou-se como um modo de resolver uma situação nova representada pela implementação da Lei. É nessa linha de pensamento que procurei compreender quais eram essas respostas criativas diante ao processo de inserção da música na escola. Para Carbonell (2002), a inovação educativa vem associada à renovação pedagógica, à mudança e à melhoria. No momento em que a novidade entra no espaço escolar ela provoca movimentos, reajustes e contratempos. Este elemento novo gera situações de conflito que, por sua vez, dão lugar a novas ideias, novos modos de fazer e interagir numa determinada situação e transformá-la.

A minha busca esteve centrada em mostrar essas encruzilhadas como respostas aos diversos momentos do processo de inserção da música no ambiente escolar, tendo como desafio o fato de revelar a vida cotidiana da comunidade estudada na textura da aparente rotina de todos os dias (ALVES, 2004). Com base nos fundamentos sobre inovação e cotidiano escolar, busquei compreender como a instituição educativa organizava seus tempos e espaços para dar origem a um novo modo de pensar a música no contexto escolar.

\section{Percursos metodológicos}

Adotei como metodologia o estudo de caso, sendo a observação e descrição das estratégias e linhas de ação escolhidas pela instituição, um dos modos de aproximação ao campo. A inserção da música, tendo a escola como campo, representa um caso intrínseco, assim, a pesquisa tem um interesse particular no caso, no

\footnotetext{
${ }^{1}$ Esta lei tornava obrigatório o ensino de música nas escolas públicas e particulares do Brasil, incluindo a
} música como conteúdo curricular da disciplina de Arte. 
qual o objetivo é aprender dele, compreendê-lo nas suas variadas formas e dimensões para chegar a uma interpretação mais autêntica possível. Segundo Stake (2010), no estudo de caso se busca o detalhe da interação com seus contextos, destacando as diferenças sutis, a sequência dos acontecimentos e a globalidade das situações pessoais.

A escola, como campo de pesquisa, é um espaço difícil de descrever e de pensar (BOURDIEU, 2011), partindo desta ideia, o que a escola representa é a soma de diferentes expressões sobre uma mesma realidade, assim, procura-se descrever e pensar a escola como um conjunto, um todo no qual convivem pessoas que se aproximam e se separam, seja no conflito, na confrontação, na compreensão ou no compromisso mútuo. Essas diferentes expressões foram organizadas pelo conjunto de entrevistas, com o objetivo de trazer à luz a representatividade do caso estudado. Dentre as técnicas utilizadas - conjuntamente às entrevistas semiestruturadas realizadas com os diferentes setores da escola e aos grupos focais com alunos - os diários e as observações teceram as redes de dados e percepções sobre a realidade estudada, permitindo confrontar, comparar e estabelecer relações dentro de um todo.

A entrevista semiestruturada e a observação participante constituíram-se como as principais ferramentas na obtenção de dados. A primeira foi realizada ainda com cada um dos participantes da pesquisa pertencentes à comunidade educativa, sejam estes: professores, equipe diretiva, famílias, funcionários e pessoas do bairro; a observação participante foi utilizada paralelamente a uma terceira técnica desenvolvida com grupos focais, técnica realizada com as turmas de alunos que transitaram pela experiência do ensino musical dentro da escola, considerando relevante para este estudo envolver as turmas dos dois primeiros anos de inserção da música no currículo, anos 2010 e 2011 respectivamente (na época, sétimas e oitavas séries do Ensino Fundamental), como mostra o quadro a seguir:

\begin{tabular}{|l|c|}
\hline Grupos alvos & $\begin{array}{l}\mathrm{N}^{\circ} \\
\text { entrevistas }\end{array}$ \\
\hline $\begin{array}{l}\text { Equipe diretiva (diretor geral, vice-diretor, coordenadora pedagógica, supervisora, } \\
\text { professoras do serviço de orientação educacional, assistente social) }\end{array}$ & 8 \\
\hline $\begin{array}{l}\text { Professores (de diferentes áreas) de alunos que receberam as primeiras aulas de música na } \\
\text { escola. }\end{array}$ & 8 \\
\hline Pessoas do bairro (comunidade externa, lojistas, outros.) & 7 \\
\hline Funcionários (setor de limpeza, tesouraria, manutenção) & 7 \\
\hline Famílias (responsáveis dos alunos que participaram das aulas de música na escola) & 6 \\
\hline TOTAL & 36 \\
\hline
\end{tabular}

As temáticas desenvolvidas através das entrevistas se relacionam com a função da música na escola, a programação do componente, o seu sustento na instituição, o impacto observado, as expectativas, a avaliação parcial do processo, o futuro da música na escola e sua contribuição na comunidade ${ }^{2}$. A partir das res-

\footnotetext{
$\overline{2}$ A escola estudada atravessou, no início da realização desta pesquisa, por etapas de transformação, de mudanças estruturais, internas e externas, no corpo docente e na equipe diretiva, mas, fundamentalmente, procurando uma mudança de visão de escola perante a comunidade escolar em geral, entre alunos, professores, famílias e funcionários da instituição. A reestruturação da instituição gerou uma nova maneira de lidar com os conflitos e dilemas do cotidiano escolar, como por exemplo, o baixo rendimento escolar, a presença de certos índices de violência na convivência entre alunos, a desmotivação e desinteresse pelas atividades escolares, dentre outros fatores.
} 
postas dos responsáveis desse processo, envolvidos em diferentes momentos da inserção da música, foi possível estabelecer as diversas categorias de análises constituindo uma fonte de dados e recursos variados na compreensão da situação observada.

O critério de seleção dos professores participantes foi estabelecendo-se a partir da realização das discussões com os grupos focais. A intenção foi estabelecer relações entre as falas dos alunos e os professores deles, fazendo inferências entre os dois grupos e procurando entrelaçar os diferentes olhares sobre o mesmo fato. No desenvolvimento das discussões com grupos focais, as respostas obtidas a partir da interação entre os participantes deram origem a uma das várias interpretações sobre a primeira temática discutida, representada aqui:

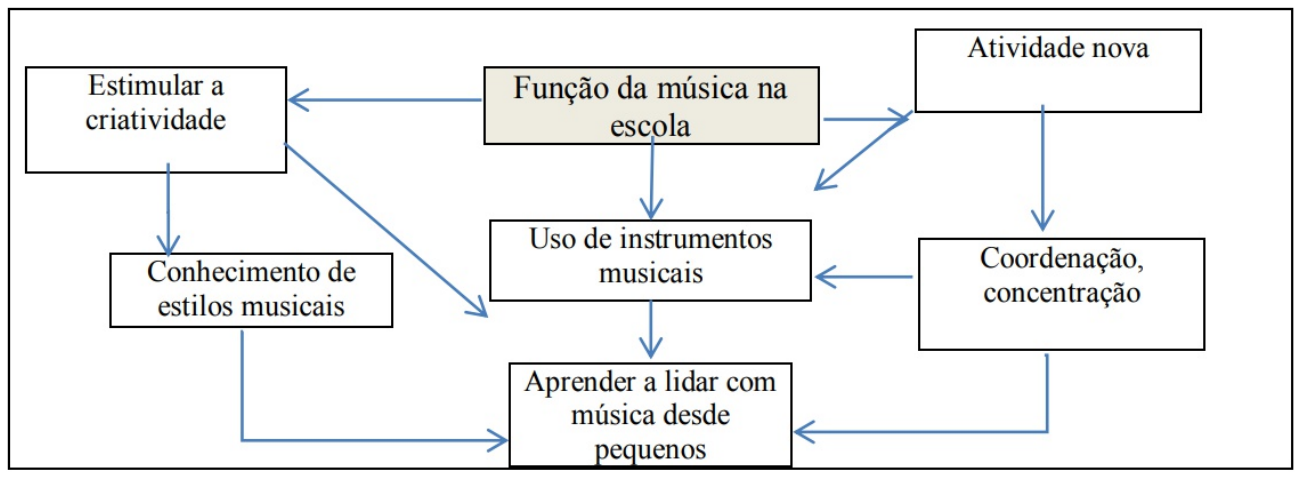

Figura 2. Codificação 1: A inserção da música na escola desde o olhar dos alunos.

Essas técnicas foram complementadas com o registro audiovisual o qual auxiliou no momento de documentar os locais onde surgiam dados relevantes para os fins da pesquisa, como por exemplo, nos recreios, nos diversos ângulos do pátio, embaixo das escadarias, no refeitório, nas festas e comemorações escolares, na preparação para algum evento, dentre outros.

O cruzamento de dados a partir dessas técnicas permitiu realizar a triangulação, (RICHARDSON, 1994; YIN, 2005) termo utilizado para analisar as vozes que deram origem a uma infinidade de variantes e gamas de "cores" extraídas dos diversos "ângulos de abordagem". No presente estudo, a realização de uma triangulação ou cruzamento de dados se encaixa fundamentalmente a partir das necessidades intrínsecas do trabalho, que envolve processos de confrontação e constatação das informações obtidas por meio de múltiplas fontes.

\section{Construindo o quebra-cabeça: categorização do corpus da pesquisa}

Utilizei a metáfora do quebra-cabeça com o intuito de definir os procedimentos de construção, de "montagem articulada" das diversas percepções, deste modo, foi possível apropriar-se dos elementos mais significativos de cada uma das peças e reconstruir as visões dessa realidade a partir da elaboração do processo de categorização. O conceito de cristalização utilizado por Richardson (2009) enfatiza "o valor de olhar simultaneamente para a mesma questão ou conceito a partir de 
uma variedade de ângulos diferentes" (RICHARDSON, 2009, p. 34), desta forma, a produção de múltiplas bases de dados paralelas permitiu aproveitar o potencial comparativo de várias fontes de dados sem pretender estabelecer uma hierarquia entre elas. $O$ seguinte quadro representa os diferentes olhares sobre a inserção da música na escola visando à comunicação entre as diversas partes do todo:

\begin{tabular}{|c|c|c|c|c|c|c|}
\hline Eixos & $\begin{array}{l}\text { Equipe Diretiva e } \\
\text { Pedagógica }\end{array}$ & Professores & Funcionários & Famílias & Bairro & Alunos \\
\hline $\begin{array}{l}\text { Fase inicial } \\
\text { do processo } \\
\text { de inserção }\end{array}$ & $\begin{array}{l}\text { Convencimento } \\
\text { da nova proposta } \\
\text { educativa da } \\
\text { música no PPP }\end{array}$ & $\begin{array}{ll}\text { Aceitação } & \text { da } \\
\text { proposta } & \text { da } \\
\text { música } & \text { no } \\
\text { currículo } & \end{array}$ & $\begin{array}{l}\text { Observação do } \\
\text { incentivo da } \\
\text { escola para a } \\
\text { continuidade } \\
\text { do projeto }\end{array}$ & $\begin{array}{l}\text { A educação } \\
\text { musical como } \\
\text { inovação no } \\
\text { currículo }\end{array}$ & & $\begin{array}{lr}\text { Visão } & \text { da } \\
\text { inserção } & \text { da } \\
\text { música } & \text { na } \\
\text { escola desde } \\
\text { as múltiplas } \\
\text { funções que } \\
\text { ela assume e o } \\
\text { lugar r que } \\
\begin{array}{lr}\text { ocupa no } \\
\text { currículo }\end{array} \\
\end{array}$ \\
\hline $\begin{array}{l}\text { Linhas de } \\
\text { ação }\end{array}$ & $\begin{array}{l}\text { Divulgação e } \\
\text { parceria com } \\
\text { outras realidades } \\
\text { educativas e com } \\
\text { a comunidade }\end{array}$ & & $\begin{array}{l}\text { Marketing } \\
\text { como } \\
\text { divulgação da } \\
\text { proposta } \\
\text { educativa com } \\
\text { a música no } \\
\text { currículo } \\
\end{array}$ & $\begin{array}{l}\text { Pouca } \\
\text { divulgação da } \\
\text { proposta }\end{array}$ & $\begin{array}{l}\text { Conhecimento } \\
\text { da proposta da } \\
\text { música na } \\
\text { escola através } \\
\text { de eventos, } \\
\text { parcerias, etc. }\end{array}$ & $\begin{array}{l}\text { Participação } \\
\text { em eventos } \\
\text { musicais que } \\
\text { envolvem a } \\
\text { comunidade }\end{array}$ \\
\hline $\begin{array}{l}\text { Comunicação } \\
\text { família- }\end{array}$ & $\begin{array}{l}\text { Valorização do } \\
\text { papel da família }\end{array}$ & $\begin{array}{l}\text { Famílias que } \\
\text { comentam } \\
\text { mudanças }\end{array}$ & & \begin{tabular}{l}
\multicolumn{2}{l}{ Participação } \\
ativa em \\
eventos
\end{tabular} & & $\begin{array}{l}\text { O que os } \\
\text { alunos falam } \\
\text { sobre a música }\end{array}$ \\
\hline escola & & $\begin{array}{l}\text { observáveis nos } \\
\text { alunos nas aulas }\end{array}$ & & $\begin{array}{l}\text { relacionados } \\
\text { com a música }\end{array}$ & & $\begin{array}{l}\text { na escola: } \\
\text { aprendizagens } \\
\text { e experiências }\end{array}$ \\
\hline $\begin{array}{l}\text { As múltiplas } \\
\text { funções da } \\
\text { música na } \\
\text { escola }\end{array}$ & $\begin{array}{ll}\text { Construção } & \text { do } \\
\text { conceito } & \text { de } \\
\text { disciplina } & \end{array}$ & Socialização & $\begin{array}{l}\text { A música nos } \\
\text { recreios no } \\
\text { cotidiano } \\
\text { escolar como } \\
\text { inovação }\end{array}$ & \begin{tabular}{lr}
\multicolumn{2}{c}{ Compreender } \\
a & música \\
como & uma \\
matéria & a \\
mais & dentro \\
da matriz \\
curricular
\end{tabular} & & $\begin{array}{l}\text { A percepção } \\
\text { de grupo como } \\
\text { um aspecto } \\
\text { positivo nas } \\
\text { aulas }\end{array}$ \\
\hline $\begin{array}{l}\text { A escola } \\
\text { como } \\
\text { organização }\end{array}$ & $\begin{array}{l}\text { Gestão } \\
\text { democrática } \\
\text { participativa da } \\
\text { escola }\end{array}$ & $\begin{array}{l}\text { Trabalho } \\
\text { interdisciplinar } \\
\text { com a música }\end{array}$ & $\begin{array}{l}\text { Valorização } \\
\text { dos eventos } \\
\text { musicais da } \\
\text { escola }\end{array}$ & & $\begin{array}{l}\text { Necessidade } \\
\text { de uma maior } \\
\text { integração } \\
\text { escola-bairro }\end{array}$ & $\begin{array}{l}\text { Contribuições } \\
\text { como uma } \\
\text { atividade } \\
\text { diferenciada, } \\
\text { nova. }\end{array}$ \\
\hline $\begin{array}{l}\text { Inovação no } \\
\text { cotidiano } \\
\text { escolar }\end{array}$ & $\begin{array}{l}\text { Novo perfil de } \\
\text { aluno (o aluno } \\
\text { como } \\
\text { protagonista } \\
\text { desenvolvendo a } \\
\text { capacidade de } \\
\text { reflexão } \\
\text { expressão através } \\
\text { da música) }\end{array}$ & $\begin{array}{l}\text { Desenvolvimento } \\
\text { da criatividade e } \\
\text { da } \\
\text { expressividade } \\
\text { do aluno aplicada } \\
\text { a outras situações } \\
\text { de aprendizagem }\end{array}$ & $\begin{array}{l}\text { Mudança de } \\
\text { comportamento } \\
\text { dos alunos }\end{array}$ & $\begin{array}{l}\text { Observação } \\
\text { de mudanças } \\
\text { através da } \\
\text { vivência dos } \\
\text { próprios } \\
\text { filhos }\end{array}$ & & $\begin{array}{l}\text { Aprendizagens } \\
\text { significativas } \\
\text { "da aula de } \\
\text { música para } \\
\text { fora" e vice- } \\
\text { versa }\end{array}$ \\
\hline $\begin{array}{l}\text { Projeção da } \\
\text { escola }\end{array}$ & $\begin{array}{l}\text { Mudança da } \\
\text { visão da escola } \\
\text { na comunidade }\end{array}$ & $\begin{array}{lr}\text { Construção } & \text { de } \\
\text { uma } & \text { nova } \\
\text { identidade } & \\
\text { escolar } & \end{array}$ & $\begin{array}{l}\text { A escola como } \\
\text { lugar de } \\
\text { pertencimento }\end{array}$ & & \begin{tabular}{lr}
\multicolumn{2}{c}{ Construção de } \\
uma & nova \\
visão & da \\
escola & no \\
bairro & \\
\end{tabular} & $\begin{array}{l}\text { Sentimento de } \\
\text { pertencer a um } \\
\text { grupo, nova } \\
\text { identidade do } \\
\text { aluno }\end{array}$ \\
\hline $\begin{array}{l}\text { Continuidade } \\
\text { do projeto }\end{array}$ & 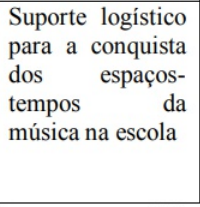 & $\begin{array}{l}\text { Retomada do } \\
\text { histórico musical } \\
\text { da banda marcial }\end{array}$ & $\begin{array}{ll}\text { Voltar } & \text { a } \\
\text { construir } & \\
\text { grupos } & \\
\text { musicais } & \text { na } \\
\text { escola } & \end{array}$ & & $\begin{array}{lr}\text { Recuperar } & \text { a } \\
\text { história da } & \text { da } \\
\text { banda } & \mathrm{e} \\
\text { oferecer maior } \\
\text { abertura da } \\
\text { escola para a } \\
\text { comunidade } \\
\end{array}$ & $\begin{array}{l}\text { Expectativas: } \\
\text { a música como } \\
\text { componente } \\
\text { independente } \\
\text { em todos os } \\
\text { níveis de } \\
\text { ensino }\end{array}$ \\
\hline
\end{tabular}

Figura 3. Base transversal de dados 
Foi possível costurar os eixos temáticos que organizaram olhares e auxiliaram no processo de interpretar como a música conectava a cada um dos integrantes desta comunidade escolar. A seguinte figura reúne as percepções sobre um mesmo tópico extraído da base transversal, neste caso, "A música na escola e a sua relação com a projeção da escola no bairro":

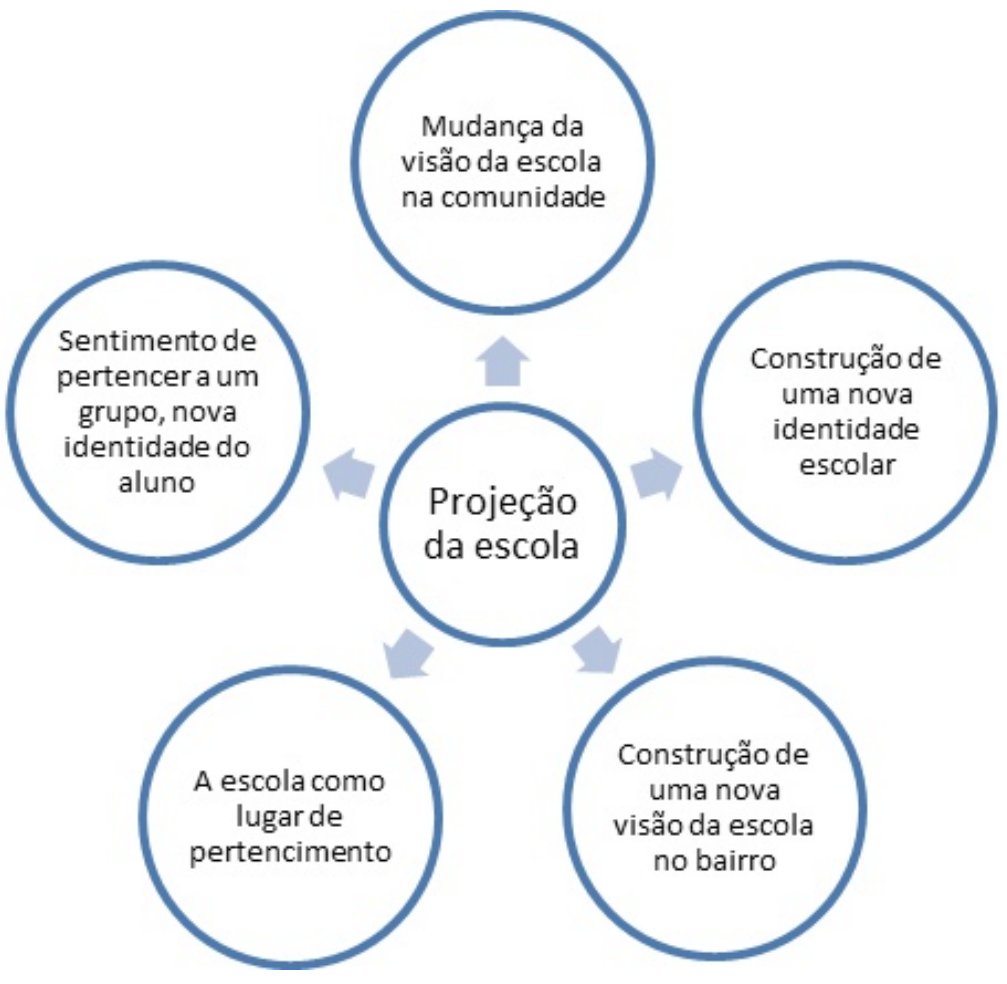

Figura 4. Inter-relações sobre o tópico "projeção da escola"

A análise desta perspectiva sugere que a projeção da escola se encontrava em relação direta com a mudança atitudinal dos alunos, relacionada com a presença da música na comunidade, e também, com o movimento de socialização entre alunos, professores, funcionários e famílias, como uma das múltiplas funções da música dentro da escola.

Ao longo do estudo foram analisadas todas as outras categorias em constante fluxo de comunicação entre as partes, mas que, por questões de espaço e formato, não serão elencadas neste artigo. As redes tecidas entre cada uma dessas categorias deram origem aos resultados apresentados a continuação.

\section{Um modelo flexível de integração da música na vida escolar}

A educação musical inseriu-se no cotidiano da escola a partir de pequenas ações buscando integrar os diferentes níveis de ensino e elementos da comunidade escolar, criando laços de comunicação, trocas e, consequentemente, aprendiza- 
gens. Esse modelo também oportunizou experiências musicais em espaços e tempos não definidos, não delimitados, não demarcados por datas, eventos escolares ou locais específicos, observou-se que a escola construiu modos de interagir com a mudança a partir dos desafios apresentados por ela mesma. Assim, a música começava a ver-se como uma parte de um todo, estabelecendo-se como um valorizado aspecto da vida escolar.

A identidade que a aula de música foi assumindo a partir deste modelo teve repercussão direta na própria concepção como conteúdo e/ou disciplina. A sua presença na escola foi construída gradativamente, passando inicialmente por algumas turmas e depois atingindo todos os níveis de ensino, como disciplina obrigatória dentro da matriz curricular. Posteriormente, como conteúdo obrigatório e não exclusivo dentro da disciplina artes, paralelamente assumindo funções de socialização fora da aula de música com a formação do grupo vocal e com as oficinas de instrumentos, culminando, em março de 2013 , com a inserção da educação musical no turno integral, oferecendo um período por semana nos turnos da manhã e da tarde.

Os ciclos observados no processo de inserção da música demonstraram um primeiro momento de estranhamento e experimentação com seis turmas dos últimos anos do ensino fundamental e um segundo momento de inclusão com o ensino musical na matriz curricular de todas as turmas atingindo os três níveis de ensino da instituição. Esses momentos foram condizentes com as expectativas que a instituição tinha em relação ao resultado da proposta, possibilitando mudanças tanto dentro quanto fora da instituição, com sua projeção no resto da comunidade.

Os diversos efeitos do processo foram vivenciados por toda a comunidade educativa, cada um de uma maneira diferente: os professores ao entrarem na sala de aula observavam que os alunos "continuam tocando o violão!" e "ficam batucando na mesa quando terminam de fazer as tarefas!" e até "eles levam os instrumentos mesmo quando não tem aula de música e ficam fazendo 'barulho' nos recreios!". As famílias tiveram contato direto com o trabalho realizado, participando das experiências envolvidas nos projetos musicais, auxiliando na restauração de instrumentos usados para dar-Ihes vida nas aulas de música, assim como nas apresentações musicais dos seus filhos na escola ou fora dela. Os funcionários, por sua vez, foram percebendo a presença da música de uma forma mais sutil, relacionando-se em forma indireta com ela, auxiliando na manutenção e construção de arquibancadas para a sala ou, por exemplo, ao perguntar "que música é aquela 'sora'?" ao fazer faxina nas escadas ou ao mencionar o porteiro que "hoje se escutou um barulho de latões que saía pela janela". Desta forma, eles trazem outras dimensões sobre o que faz a música no cotidiano escolar.

A divulgação da música como proposta educativa da escola dentro do seu próprio ambiente foi necessária para a construção e valorização do espaço da educação musical. O caminho que a música começou a traçar dentro da escola era desconhecido por muitas pessoas que faziam parte do convívio escolar, até que a música começou a ser percebida em suas intervenções e movimentos no interior do seu próprio ambiente como é mencionado por um dos membros da equipe diretiva ao dizer que: 
tenho "observado" sons pelos corredores, não só dentro do prédio, mas também nas vizinhanças e isso tudo causa certas inquietudes de interesses por parte da comunidade... tem aparecido pessoas que vem matricular os filhos perguntando se tem música na escola para que seu filho tenha esta chance, essa oportunidade. (Trecho extraído da entrevista com o vice-diretor, 30 de Setembro, 2011).

A implementação da Lei facilitou/viabilizou a presença da música no colégio, assumindo diversas modalidades seja como oficina, como conteúdo ou como componente dentro da matriz curricular. O lugar que a música ocupa atualmente nesta escola é diretamente proporcional ao envolvimento de cada uma das suas partes. A necessidade e o desejo de trazer a música para dentro dela nasceram como uma meta desde a gestão escolar, mas somente poderia alcançar os seus objetivos concretos com a participação de todos.

Os alunos comprometidos com a presença da música na escola e construindo significados, os professores articulando os seus próprios projetos com as atividades musicais mais diversas, as famílias assumiram um papel mais participante e envolveram-se diretamente com a proposta, os funcionários se mostraram receptivos às necessidades que iam surgindo em função desta nova presença, finalmente, a abertura da escola diante do seu próprio contexto social. Cada um deles interagiam na inserção da música na escola, um processo em constante construção, uma vez que a inclusão da música no projeto pedagógico da instituição é decisiva para a sua manutenção e fortalecimento. A partir deste momento, a educação musical assumirá uma função determinante na reconstrução da identidade escolar.

\section{Algumas considerações}

O elemento essencial, comum a toda escola que inova é a disposição para a mudança e o envolvimento de/com cada uma das partes. A partir da inserção da música no cotidiano escolar, destacam-se ainda os ganhos relativos ao resgate da imagem social da escola segundo os diversos relatos. Considerando os caminhos que a educação musical foi trilhando ao estudar os seus processos de inserção posso afirmar que a presença da música nessa escola tem seu embasamento no compromisso assumido pela comunidade em geral. Ao perguntar à professora de geografia, qual seria a contribuição que a música poderia dar à instituição, vale a pena destacar o seu depoimento na íntegra:

na geografia a gente tem dois conceitos que são os que eu trabalho: lugar e não lugar. Lugar, resumindo, seria quando tu se identifica com o local, com o ambiente onde tu estás convivendo; não lugar é quando tu não tem identidade, aquele lugar pra ti é só um lugar de passagem. Até então, ao meu entender, os alunos aqui não conseguem se identificar com a escola, pra eles a escola é um não lugar [...] mas eu percebo que eles estão mudando aos poucos essa visão, eles já estão transformando a escola num lugar pra eles. E eu percebo que a músi- 
ca está tornando esse processo mais rápido, a partir do momento que eles começam a se orgulhar deles, eles começam a perceber também que a escola está proporcionando outras coisas também, que a escola está se tornando um lugar com um pouco mais a cara deles... porque até então a escola não tinha relação nenhuma com eles e eu passo a não gostar do que estou fazendo e consequentemente do meu ambiente, do lugar aonde eu estou, então o ambiente se torna distante e eu acho que a música tem feito isso assim, tem transformado o colégio de um não lugar pra um lugar aonde se identificam, aonde eles estão gostando. (Trecho extraído da entrevista com a professora de Geografia, 29 de Setembro, 2011)

Ao considerar a necessidade da reconstrução de uma identidade escolar a partir do reconhecimento da escola como lugar, observou-se que esse cotidiano que se estabelece no lugar é um cotidiano compartido entre as mais diversas pessoas no qual cooperação e conflito são a base da vida em comum. Através dos depoimentos ficou evidenciado que as mudanças de atitudes e de condutas nos alunos, eram originadas por transformações internas e por um processo que tinha a ver com o fato de se sentir parte de um lugar, uma sensação de pertença em relação à escola, começando a se identificar com isso ao ver "coisas boas" acontecendo.

Nas palavras da professora de geografia achei o significado de muitas das perguntas que surgem quando uma proposta educativa, uma aula planejada ou uma atividade realizada não atinge as expectativas do professor, quando não produzem nos alunos os resultados almejados. Segundo a professora, esse sentir-se pertencente a um lugar - neste caso a escola - poderia ser construído a partir de experiências nas quais o aluno se sinta partícipe e promotor das mesmas. Essa reflexão me fez repensar sobre o papel da música nessa reconstrução da identidade escolar, quais os seus procedimentos e efeitos palpáveis que me permitissem ver as mudanças nas diferentes dimensões da comunidade escolar e especialmente nos alunos, artífices da transformação.

\subsection{Os limites e desafios nesta investigação}

Os limites desta investigação se centram no processo específico que uma instituição de ensino particular atravessou ao inserir a educação musical no seu cotidiano escolar, contribuindo com mudanças intrínsecas e extrínsecas, provocando pequenas inovações dentro da sua comunidade, gerando espaços-tempos escolares aonde a música se estabeleceu como um nexo entre os vários atores educacionais: aluno - professor - equipe diretiva - funcionários - família - pessoas do bairro.

Este estudo de caso propõe a observação dos possíveis percursos que a educação musical pode escolher para trilhar o seu caminho de inserção num determinado ambiente escolar, com as suas próprias dificuldades, oportunidades, alcances, desafios e limitações. Destaco, neste momento particular de extremas mudanças políticas, sociais e econômicas que atingem todas as esferas de uma sociedade, as conquistas da educação musical como área nesta realidade, a realização de eventos dos mais variados tipos e formatos realizados pela Associação 
Brasileira de Educação Musical (ABEM) e por tantas outras iniciativas públicas e privadas que são conscientes da importância da continuidade e manutenção de projetos, de ideias criativas e inovadoras e da força dos movimentos coletivos.

A definição dos rumos da educação musical no ambiente escolar está intimamente relacionada com a inclusão da música no projeto pedagógico e as concepções sobre currículo participativo, estabelecidas ao longo do processo de inserção. Torna-se necessário repensar e questionar os modos em que a inovação se sustenta e conquista seus espaços dentro dessa realidade. Relembrando Morin (2002), "nenhum progresso é uma aquisição para sempre" e neste panorama, a conquista dos espaços da música na escola não culmina somente com a implementação de políticas públicas, visto que o caminho de fortalecimento da área é fundamental na tomada de consciência da necessidade de fortalecimento do espaço conquistado e da manutenção dos mecanismos e os processos que levam à inserção da música no ambiente escolar. Para seguir avançando nessa direção, deverão ser superados ainda muitos obstáculos. Como educadores musicais temos o dever de exigir das autoridades a elaboração e avaliação de planos estaduais e/ou municipais para a implementação do ensino de música nas diferentes redes e contextos de ensino.

Neste texto transitei por temáticas que vem ao encontro das necessidades de adaptação da música à escola como uma situação nova que transcende os alcances da própria legislação. Essa adaptação está relacionada às políticas internas da instituição e aos processos de inovação escolar gerada pela própria inserção, à influência de uma gestão democrática participativa e às visões sobre/para/com a música na escola por parte dos diferentes atores envolvidos nesse processo.

Tendo consciência de que cada escola constitui um cenário diferente, uma realidade única, este relato procurou oferecer algumas possibilidades quanto a inserção da música num determinado contexto escolar, observando os processos que envolvessem as práticas musicais no cotidiano e intuindo compreender melhor os reflexos da presença dessas práticas em toda a comunidade participante. Espera-se que os resultados deste estudo possam constituir-se como um material de apoio, reflexão e avaliação das diferentes modalidades e visões de construção do espaço da música no ambiente escolar.

\section{REFERÊNCIAS}

CAGUERRONDO, Maria Inês. Cómo piensan las escuelas que innovan. Buenos Aires: Papers, 2002.

ALVES, Nilda. Decifrando o pergaminho: O cotidiano das escolas nas lógicas das redes cotidianas. In: OLIVEIRA, I., ALVES, N. (Org.). Pesquisa no/do cotidiano das escolas: sobre redes de saberes. Rio de Janeiro: DP\&A, 2001.

ALVES, Nilda; OLIVEIRA, Inês Barbosa de. Imagens de escolas: espaçostempos de diferenças no cotidiano. Educação Social, Campinas, v. 25, n. 86, p. 17-36, abr. 2004.

BOURDIEU, Pierre. (Coord.). A miséria do mundo. 8. ed. Petrópolis: Vozes, 2011. 
BRASIL. Lei no 11.769/2008. Altera a lei no 9.394/96, de 20 de dezembro de 1996, Lei de Diretrizes e Bases da Educação para dispor sobre a obrigatoriedade do ensino de música na educação básica. Brasília, DF: 2008. Disponível em: http://www.planalto.gov.br/ccivil_03/_Ato2007-2010/2008/Lei/L11769.htm. Acesso em: 04 jun. 2009.

CARBONELL, Jaume. A aventura de inovar: a mudança na escola. Fátima Murad (trad.). Porto Alegre: ArtMed, 2002.

CARBONELL, Jaume. et al. Aprendiendo de las innovaciones en los centros: la perspectiva interpretativa de investigación aplicada a tres estudios de caso. Barcelona: Octaedro, 1998.

CERTEAU, Michel de. A invenção do cotidiano: artes de fazer. Petrópolis: Vozes, 1994.

HELLER, Agnes. O Cotidiano e a História. 6. ed. São Paulo: Paz e Terra, 2000.

MORIN, Edgar. La cabeza bien puesta: repensar la reforma, reformar el pensamiento. Buenos Aires: Nueva Visión, 2002.

NÓVOA, Antonio. Professores imagens do futuro presente. Lisboa: Educa, 2009.

PAIS, José Machado. Nas rotas do quotidiano. Revista Crítica de Ciências Sociais, n. 37, jun. 1993.

RICHARDSON, L. Writing: a method of inquiry. In: Denzin, N. e Lincon, Y. (Ed.). Handbook of Qualitative Research. Londres; Nova lorque: Sage, 1994.

RICHARDSON, L. Pesquisa Social: métodos e técnicas. 3. ed. São Paulo: Atlas, 2009.

SOUZA, Jusamara Vieira. O cotidiano como perspectiva para a aula de música. In: (Org.). Música,

Cotidiano e Educação. Porto Alegre: Programa de Pós-Graduação em Música do Instituto de Artes da UFRGS, 2000.

SOUZA, Jusamara Vieira (Org.). Aprender e ensinar música no cotidiano. Porto Alegre: Sulina, 2008.

STAKE, Robert. Investigación con estudios de caso. Tradução Roc Filella, 5. ed. Madrid: Eduiciones Morata, 2010.

TEDESCO, Juan Carlos. O novo pacto educativo. São Paulo: Ática, 2001.

YIN, Robert. Estudo de caso: planejamento e métodos. 3. ed. Porto Alegre: Bookman, 2005. 
Como citar:

LOPARDO, C. E. (2019). A inserção da música na escola: processos e resultados de uma pesquisa. OuvirOUver, 15(2), 16-29. https://doi.org/10.14393/OUV24-v15n1a2019-1

(c) (7) \&) A revista ouvirOUver está licenciada com uma Licença Creative 